\title{
DETECTION AND QUANTIFICATION OF INDUSTRIAL METHANE PLUME WITH THE AIRBORNE HYSPEX-NEO CAMERA AND APPLICATIONS TO SATELLITE DATA
}

\author{
N. Nesme ${ }^{1,2}$, P.-Y. Foucher ${ }^{2}$, S. Doz ${ }^{2}$ \\ ${ }^{1}$ SPASCIA, Spatial Science Algorithmics, 31520 Ramonville Saint-Agne, France - nicolas.nesme-ext@ onera.fr \\ ${ }^{2}$ Dept. Optics and Associated Technics DOTA, ONERA, 31400 Toulouse, France - (pierre-yves.foucher, stephanie.doz)@ onera.fr
}

KEY WORDS: Hyperspectral, Methane, Quantification, Remote sensing, SWIR

\begin{abstract}
:
The control and monitoring of greenhouse gases is an important issue for the study of climate change, for the impact in terms of public health or for the risks related to industry. An algorithm has been developped dedicated to commercial airborne hyperspectral camera as HySpex-NEO for the detection of industrial methane plume and the quantification of the emission source. HySpex-NEO is an imager used in airborne campaign with a spatial resolution of $1.4 \mathrm{~m}$ at flight altitude of $2 \mathrm{~km}$, a swath of $650 \mathrm{~m}$ and a spectral resolution of $6 \mathrm{~nm}$. This algorithm has been validated over a controlled release less than $100 \mathrm{~g} / \mathrm{s}$ during an airborne campaign over Lacq (France) industry. It has also been applied to the Aliso Canyon leakage data acquired with AVIRIS JPL (Airborne Visible Infrared Spectrometer) with a spatial resolution of $6.8 \mathrm{~m}$ at flight altitude of $6 \mathrm{~km}$, a swath of $5.6 \mathrm{~km}$ and a spectral resolution of 10 $\mathrm{nm}$. Application to satellite hyperspectral data is shown on artificial data derived from airborne hyperspectral acquisitions.
\end{abstract}

\section{INTRODUCTION}

The control and monitoring of greenhouse gases is a scientific, societal, public health and environmental issue. The reduction of anthropogenic gas emissions federates countries around the Paris Agreement (2015). Methane $\left(\mathrm{CH}_{4}\right)$ influences climate as the second most important anthropogenic greenhouse gas and air quality factor (Forster et al., 2007). Carbon dioxide $\left(\mathrm{CO}_{2}\right)$ has a higher concentration than $\mathrm{CH}_{4}$ in the atmosphere but $\mathrm{CH}_{4}$ has 21 times the radiative forcing power of $\mathrm{CO}_{2}$ (Lelieveld et al., 1998, Griggs, Noguer, 2002). The atmospheric residence time of $\mathrm{CH}_{4}$ about 7.9 years (IPCC et al., 2007) is shorter than that of $\mathrm{CO}_{2}$ (one hundred years), which explains the collective efforts to reduce $\mathrm{CH}_{4}$ emissions.

While anthropogenic sources of $\mathrm{CH}_{4}$ accounted for 4-34\% in pre-industrial era (Houweling et al., 2000), they amounted to about $60-70 \%$ in 1998. Global atmospheric $\mathrm{CH}_{4}$ has increased significantly with about $0.65 \mathrm{ppm}$ in the pre-industrial epoch for about $1.8 \mathrm{ppm}$ today (Etheridge et al., 1998, Dlugokencky et al., 2009). In addition, sources and sinks of $\mathrm{CH}_{4}$ emissions are scattered randomly on Earth and show a high degree of interannual variability (Bousquet et al., 2006). If we focus on anthropogenic emissions, the main sources of $\mathrm{CH}_{4}$ emissions are energy sector (fossil fuel production, ...), agriculture (domestic ruminants, rice cultivation, ...), industry and waste treatment (Kirschke et al., 2013).

One of the powerful tools for the detection and quantification of gas emissions is hyperspectral remote sensing. It is based on the fact that the spectral signal received by a hyperspectral sensor is affected by the potential presence of a plume in the line of sight. There are two kinds of hyperspectral instruments. The first kind is satellite sounders as IASI-NG (Crevoisier et al., 2014) or TROPOMI (Veefkind et al., 2012) with a spatial resolution greater than $7 \times 7$ kilometers. This resolution allows studying very large scale plumes such as the volcanic eruptions or the evolution of background concentrations. However, it is not adapted to industrial plumes with subkilometric spread. To overcome this spatial resolution matter, hyperspectral imagers in the short-wavelength infrared (SWIR) domain are used either in airborne campaigns or more recently onboard satellites. The flight altitude of airborne imagers leads to finer spatial resolutions than satellite instruments. For altitudes under $2 \mathrm{~km}$, the ground resolution is metric (Bradley et al., 2011, Thorpe et al., 2016). But such campaigns are expensive to implement and cover a small area. The new hyperspectral satellites would make data more accessible and remove the locks related to cost and spatial coverage. However, due to a larger ground pixel size (30 m for PRISMA (Labate et al., 2009) and EnMap (Guanter et al., 2015)) and higher atmospheric absorption, the ability of satellites to detect and quantify $\mathrm{CH}_{4}$ plumes has yet to be demonstrated. The section 2 shows the sets of data available. The section 3 explains the three steps required to obtain a source flow rate estimation. The section 5 is dedicated to the algorithm results in the case of available satellite data.

\section{DATA SITES}

The results presented in this paper come from two airborne data sets. The first have been acquired by the HySpex camera, during a campaign above Lacq industries (France) in June 2017. The hyperspectral camera was a SWIR imager with a spatial resolution of $1.4 \mathrm{~m}$ at flight altitude of $2 \mathrm{~km}$ with a swath of $650 \mathrm{~m}$ and a spectral resolution of $6 \mathrm{~nm}$. The spectral range of acquisitions extends from $967 \mathrm{~nm}$ to $2501 \mathrm{~nm}$ with 256 bands. Of all the existing chimneys on the site, one platform was designed as a testing area to release gas in controlled way to simulate accidental gas leaks. In such a way that for each release, the in situ flow rate is recorded.

A second set of data were acquired by the Airborne Visible/Infrared Imaging Spectrometer (AVIRIS) which provides 224 spectral bands with a spectral resolution of $10 \mathrm{~nm}$. To reduce the size of the initial hyperspectral data, a selection of the 160 spectral bands between 966 and $2495 \mathrm{~nm}$ is applied. A spatial resolution of $6.8 \mathrm{~m}$ are obtained with the Twin Otter aircraft from the Aliso Canyon (USA). Aircraft flew over a $\mathrm{CH}_{4}$ 
superemitter during the explosion of natural gas wells in 2015 (Thompson et al., 2016).

The initial size of image is $320 \times 2607$ pixels for HySpex and 829 x 3966 pixels for AVIRIS. During the development of the algorithm, only a section around the chimney is taken, reducing the size to $170 \times 285$ pixels for HySpex and to $650 \times 1000$ pixels for AVIRIS. A representation of these two data is plotted in the figure 1 .
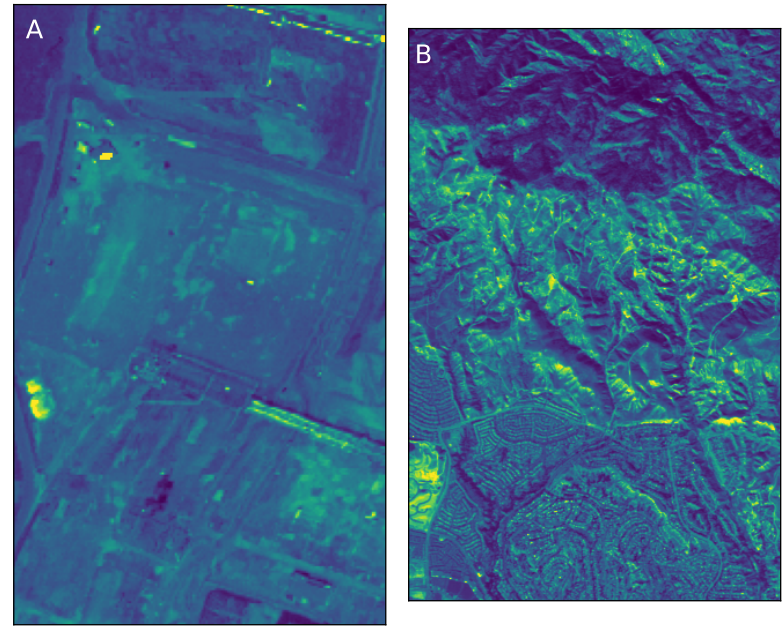

Figure 1. A : Section of the HySpex data above the chimney of the Lacq industries. B : Section of the AVIRIS data. The two images are displayed at $2.3 \mu \mathrm{m}$.

\section{METHODS}

The principle of the algorithm is based on estimation the transmission of the observed plume to estimate its integrated concentration pixel by pixel. Therefore, a first detection step allows to separate plume-present pixels to plume-absent pixels, using Cluster-Tuned Matched Filter (CTMF) algorithm. Then, the quantification method developed in this paper can be applied to identified plume-present pixels.

\subsection{Direct model of measured radiance}

The total radiance measured by the instrument can be expressed as :

$$
L_{t o t}=R \frac{E_{0} \cdot\left(\tau_{d i r}+\tau_{d i f f}\right)}{\pi(1-R S)}+L_{a t m}
$$

where $\quad L_{t o t}=$ total measured radiance (in $\mathrm{W} / \mathrm{m}^{2} / \mathrm{sr} / \mu \mathrm{m}$ )

$R=$ ground reflectance

$E_{0}=$ solar irradiance (in $\left.\mathrm{W} / \mathrm{m}^{2} / \mu \mathrm{m}\right)$

$\tau_{\text {dir }}=$ direct transmission

$\tau_{\text {diff }}=$ effective contribution of scattering effects

$S=$ spherical albedo

$L_{a t m}=$ atmospheric radiance $\left(\right.$ in $\left.\mathrm{W} / \mathrm{m}^{2} / \mathrm{sr} / \mu \mathrm{m}\right)$

A sensitivity study of the impact of each term of equation 1 with COMANCHE radiative code (Poutier et al., 2002) leads to several simplifications. The $(1-R S)$ term tends to 1 on the range of reflectance and spherical albedo. At $2.3 \mu \mathrm{m}$, the scattering phenomena are negligible compared to the absorption. Therefore, the atmospheric radiance and the scattering transmission can be deleted of equation (1). The direct transmission corrresponds to the atmospheric transmission $\left(\tau_{a t m}\right)$ multiplied by the $\mathrm{CH}_{4}$ transmission $\left(\tau_{c h_{4}}\right)$. The $\mathrm{CH}_{4}$ transmission is composed of the downward transmission and the upward transmission (affected by the zenith angle $\theta$ of the sun). These transmissions can be expressed as the total $\mathrm{CH}_{4}$ transmission :

$$
\tau_{c h_{4}}=\exp \left(-\rho A_{g a s}\left(1+\frac{1}{\cos \theta}\right)\right)
$$

To obtain the plume spectral signature from the total radiance, we use :

$$
\begin{gathered}
L_{n o p l}=R \frac{E_{0} \tau_{a t m}}{\pi} \quad(3) \quad L_{p l}=R \frac{E_{0} \tau_{a t m} \tau_{c h 4}}{\pi} \\
\frac{L_{p l}-L_{n o p l}}{L_{n o p l}}=\tau_{c h_{4}}-1
\end{gathered}
$$

where $L_{p l}$ is the measured radiance and $L_{n o p l}$ is the reference radiance (no plume radiance).

\subsection{Quantification algorithm}

\subsubsection{Preprocessing step}

A preprocessing is needed to define the wavelengths that will be used at different steps of the processing of hyperspectral data. This step consists of obtaining the transmission of the atmospheric gas. We consider that the transmission of all the gases present in the atmosphere can be approximated by the water transmission due to its high relative concentration. Using the monochromatic gas absorption (Sharpe et al., 2004), the target gas transmission is computed with the following relation :

$$
\tau_{\text {gas }}\left(\lambda_{c}\right)=\int e^{-\rho A_{\text {gas }}(\lambda)} S(\lambda) d \lambda
$$

where $\quad \lambda_{c}=$ band center wavelength (in $\mathrm{nm}$ )

$\tau_{\text {gas }}=$ transmission of the gas

$\rho=$ concentration in particle per million per meter (in ppm.m)

$A_{\text {gas }}(\lambda)=$ monochromatic unitary absorption $(\lambda$ in $\mathrm{nm})$ $S(\lambda)=$ spectral sensitivity of the instrument

This equation leads to the gas transmission at the wavelengths of the chosen instrument by using typical value of water and $\mathrm{CH}_{4}$ concentration (respectively $10^{7}$ ppm.m and $10^{5}$ ppm.m). The algorithm calculates the transmission of water and $\mathrm{CH}_{4}$ by taking into account the spectral sensitivities of AVIRIS or HySpex. The SWIR spectrum is affected by the large water absorption bands around 1.4 and $1.9 \mu \mathrm{m}$. $\mathrm{CH}_{4}$ has also absorption bands at 1.65 and $2.3 \mu \mathrm{m}$.

\subsubsection{Classification}

The classification is applied by using the k-means function of Python 3.6 to cluster each hyperspectral pixel into a class number $N$ (typically 15). The algorithm runs a first classification with $N$ classes. All classes with few pixels are deleted and a second classification is running without taking into account these isolated pixels. The two previous classifications are running without the need to initialize class centers and with 300 iterations. An example of the classification result for HySpex data is shown on the figure 2 . 


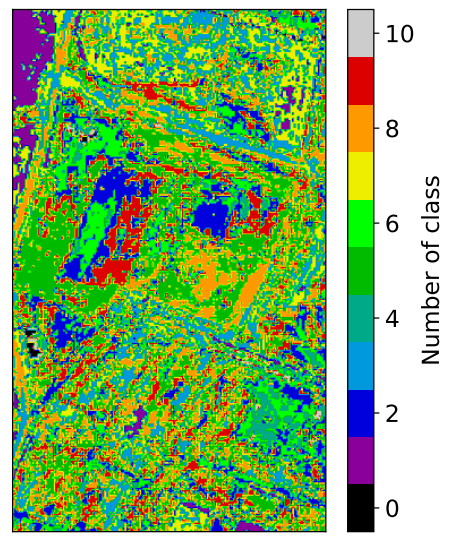

Figure 2. Classification of the HySpex image. The initial number of classes of 15 is reduced to 12 classes with the processing of pixels with few pixels. The class 0 regroups the pixels of classes with few pixels.

\subsubsection{Detection}

The detection step of the algorithm is based on the CTMF algorithm (Funk et al., 2001). Its aims to look for $\mathrm{CH}_{4}$ transmission spectral features in the hyperspectral data class by class. The CTMF algorithm and previous versions (Thorpe et al., 2014, Thompson et al., 2015, Hulley et al., 2016) take into consideration the theoretical transmission of a target gas to determine the level of similarity of each pixel to this theoretical spectrum. A high CTMF score reflects that this pixel is impacted by the target gas. This method assumes that the measured radiance can be expressed as a linear combination of the target gas signature and the signal of the rest of the scene as :

$$
L=\alpha b+L_{b k g}
$$

where $\quad L=$ at sensor radiance

$b=$ spectral signature of the target gas

$\alpha=$ strength of the plume gas

$L_{b k g}=$ radiance of the scene without plume

If we apply the CTMF method, the $L$ of the equation (7) corresponds to the left term of the equation (5) and the $b$ of the equation (7) is equal to $\tau_{c h_{4}}-1$. In addition, we define the optimum filter vector $q$ of the equation (8) and we apply it on the hyperspectral data following the equation (9) :

$$
q=\frac{\Sigma_{i}^{-1} b}{\sqrt{b^{T} \Sigma_{i}^{-1} b}} \quad \text { (8) } \quad \mathrm{CTMF}=q^{T} \frac{L_{p l}-L_{n o p l}}{L_{n o p l}}
$$

In order to obtain the CTMF score, we applied the $q$ vector to the hyperspectral image using the equation (9). The CTMF score is shown in the figure (3) after applying a mask by threshold value.

\subsubsection{Transmission estimation}

The plume transmission is directly linked to the concentration as in the equation (2). But, the $\mathrm{CH}_{4}$ transmission requires to
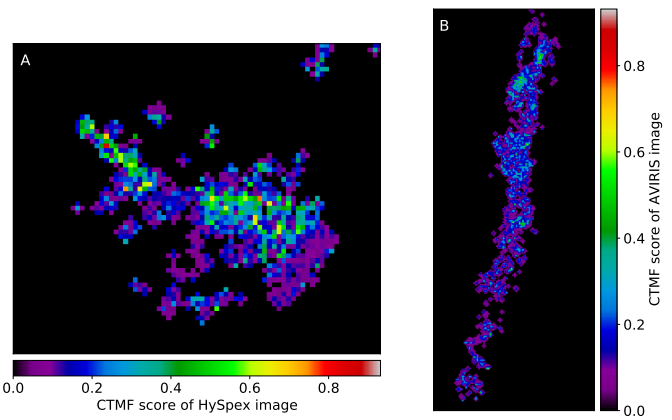

Figure 3. A : CTMF score for HySpex zoomed on the plume. B : CTMF score for AVIRIS zoomed on the plume.

determine the reference radiance $L_{n o p l}$ as shown by the equation (5). The goal of this step is to retrieve the spectrum of each pixel if the gas plume was not present. Using morphological transformations, a mask with the pixels that surround the plume is created. For each pixel of the plume, the reference is chosen among pixels of surrounding mask. To chose this specific pixel, 3 criteria are used : i) belonging to the surrounding mask, ii) belonging to the same class than the plume pixel, iii) having a spectrum similar to plume pixel at the wavelength not impacted by $\mathrm{CH}_{4}$ (by minimisation of the root-mean square error RMSE). The figure 4 represents an example of the chosen spectrum to rebuild the reference image. The blue and red curves are similar outside the $\mathrm{CH}_{4}$ range and we can observe small variations between 2.25 and $2.4 \mu \mathrm{m}$. Reference spectra become available for all detected pixels.

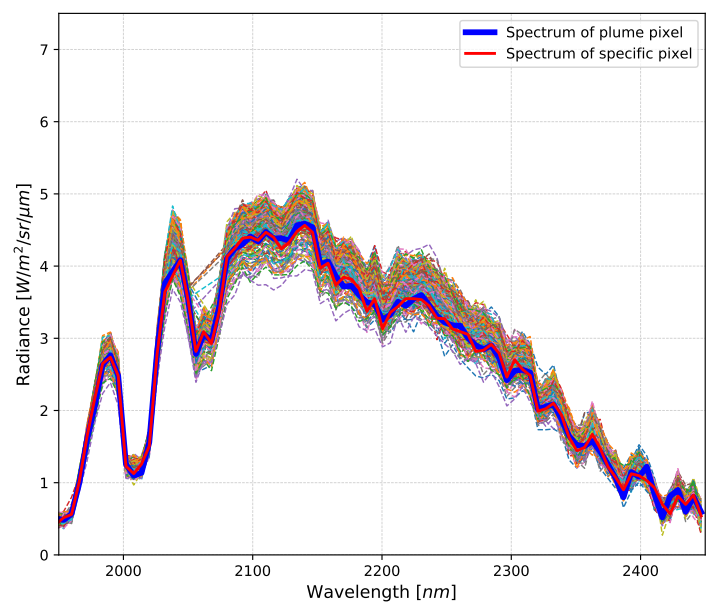

Figure 4. Spectral radiance of HySpex image pixels. The blue curve corresponds to one random pixel of the plume while the red curve is the specific pixel chosen by minimisation of the RMSE. The other thin curves represent all pixels of the same

blue pixel class and in the surrounding of the plume

Reference spectra without plume are used to provide the observed transmission following the equation (5). Then, the comparison between this transmission and theoretical transmissions from a Look-Up Table (LUT) gives access to the concentration of the plume. 


\section{APPLICATION TO AIRBORNE LEVEL}

\subsection{Detection and concentration map}

A LUT of $\mathrm{CH}_{4}$ transmission has been created (from equation (6)) from 0 to $500000 \mathrm{ppm} . \mathrm{m}$ for each instrument. For each plume pixel, the selected concentration corresponds to the minimum RMSE between the LUT transmissions and the measured transmission as given in the equation (5).

The figure 5 shows the concentration map of the HySpex (5A) and AVIRIS (5B) data. The emission point is identifiable in the both images and the algorithm detects in one the hand the main plume and on the other hand some areas around the plume that may be false alarms or gas accumulation locations.
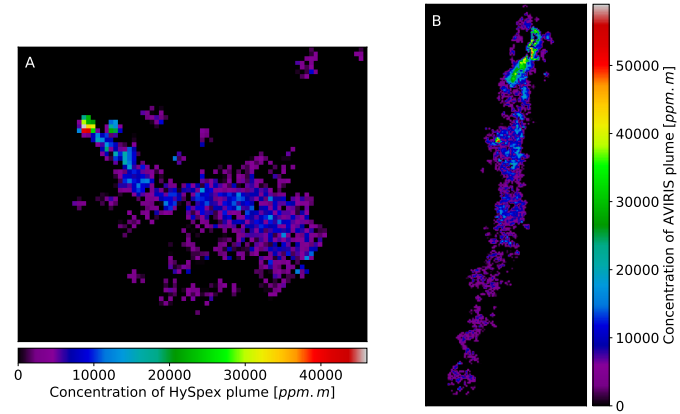

Figure 5. A : Zoom on the concentration map in ppm.m for the HySpex plume. B : Zoom on the concentration map in ppm.m for the AVIRIS plume.

\subsection{Estimation of the flow rate}

Determining the flow rate of a source is important to quantify industrial sources or natural leaks. In this paper, we chose to determine the flow rate using the central part of the plume, called "plume center" in opposition to the head (at the chimney localisation) and the plume tail (where the plume is largely dispersed). The figure $6 \mathrm{~A}$ shows the entire concentration map of the HySpex image. The figure $6 \mathrm{~B}$ represents a zoom on the plume after a rotation of $45^{\circ}$. The next step is to reduce the plume to a line by summing the concentrations belong to the width of the plume perpendicular of the flow direction (a sum by columns in this case). The mass per unit length is plotted in the figure $6 \mathrm{C}$.

The flow rate of the chimney can be obtained from the figure $6 \mathrm{C}$ by taking into account the mean of the mass per unit length. In this HySpex case, the mean of the mass per unit length is equal to $51 \mathrm{~g} / \mathrm{m}$.

To obtain an estimation of the flow rate, the last step is to multiply the mean mass per unit length by the wind speed. During the Lacq campaign, several sensors measured the speed of the wind at different altitudes. A lidar system ZEPHIR has recorded the wind with a frequency around $15 \mathrm{~s}$ at $11 \mathrm{~m}$ altitude (and other levels) and a sonic 3D instrument called METEK has measured the wind speed at $10 \mathrm{~m}$ of altitude every minute. During the Lacq campaign, the wind was very variable in strength and in direction as shown in the figure 7 for the wind speed. As we can see in the figure 7B, in only 2 minutes, the speed of the wind varies from 0.78 to $5.09 \mathrm{~m} / \mathrm{s}$ for ZEPHIR data at $11 \mathrm{~m}$ of altitude and from 1.52 to $3.98 \mathrm{~m} / \mathrm{s}$ for the METEK data at $10 \mathrm{~m}$. With the mean of the mass per unit length of $51 \mathrm{~g} / \mathrm{m}$ and a wind

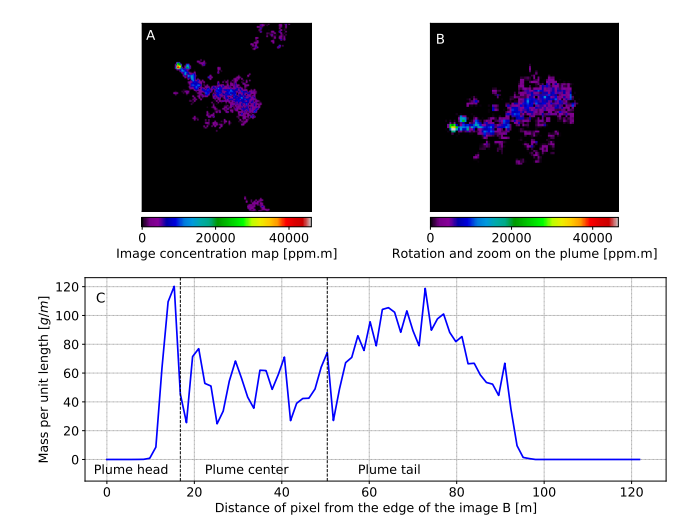

Figure 6. A : Concentration map of the entire image (in ppm.m) for HySpex acquisition. B : Concentration map after a rotation of $45^{\circ}$ and a zoom on the plume. C : Mass per unit length (in $\mathrm{g} / \mathrm{m}$ ) along the plume (in $\mathrm{m}$ )
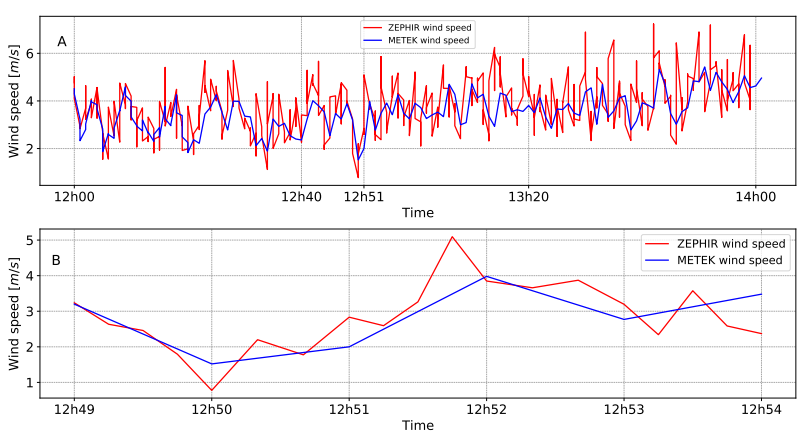

Figure 7. A : Horizontal wind speed (in $\mathrm{m} / \mathrm{s}$ ) during 1 hour before and 1 hour after the airborne flight. $\mathrm{B}$ : Horizontal wind speed (in $\mathrm{m} / \mathrm{s}$ ) zoomed around $12 \mathrm{~h} 51$, the image acquisition time.

speed ranging from 1 and $4 \mathrm{~m} / \mathrm{s}$, the algorithm estimates a flow rate between 51 and $204 \mathrm{~g} / \mathrm{s}$ for the HySpex image.

The in situ measurement of the flow rate is to $75 \mathrm{~g} / \mathrm{s}$. The last value lies in the estimation range provided by our algorithm. Several points can explain the large range of the flow rate derived by the algorithm. The first point is related to the acquisition of measurements. In this respect, we have to note that the hyperspectral image acquisition is not a snapshot and during this acquisition flight, the wind can change significantly. Due to the temporal standard deviation, the measurement of the wind speed brings a lot of uncertainties to the flow rate estimation. In addition, the wind speed is measured at $10 \mathrm{~m}$ by the instruments while the emission source is close to the ground. This point can introduce a overestimation of flow rate because the wind is stronger as the altitude is increasing. However, even if the flow rate seems to be overestimated, the in situ value is in the uncertainty range. To conclude the airborne data part, we have developed an algorithm which estimate the flow rate of a source from SWIR hyperspectral data combining with wind data. The obtained results are in good agreement with in situ measurement despite the large uncertainty of the wind speed data. 


\section{APPLICATION TO SATELLITE LEVEL}

The final purpose of this article is to demonstrate the ability of our algorithm to detect and quantify plumes with satellite data. The atmospheric layer above the airborne sensor is significant and the ground pixel size is larger from satellite than from airborne images. The following section of this paper will be dedicated to i) add the atmospheric layer above the airborne and ii) downgrade the spatial resolution. This part focuses on the AVIRIS data.

\subsection{Top Of Atmosphere level}

The initial data are recorded during airborne campaigns with 6 $\mathrm{km}$ flight altitudes by the AVIRIS imager. The satellite data will be acquired at more than $850 \mathrm{~km}$. We have to take into consideration that the signal will pass through a significant additional atmospheric path. As in the previous part, we assume that the corresponding layer is only composed to water vapor. Using the radiative transfer code COMANCHE (Poutier et al., 2002), we run simulations to determine the direct upward transmission of the atmosphere between flight altitude campaign and the top of atmosphere (TOA). The initial radiance is then affected by this term following :

$$
L_{(i m a, T O A)}=L_{(i m a, f l y)} \cdot \tau_{(f l y-T O A)}
$$

where $\quad L_{(i m a, T O A)}=$ radiance in the TOA level (in $\mathrm{W} / \mathrm{m}^{2} / \mathrm{sr} / \mu \mathrm{m}$ )

$L_{(i m a, f l y)}=$ radiance of airborne campaign (in $\mathrm{W} / \mathrm{m}^{2} / \mathrm{sr} / \mu \mathrm{m}$ )

$\tau_{(f l y-T O A)}=$ direct transmission between the airborne and the top of atmosphere (TOA)

As mentioned on the section 3.2.3, the scattering terms (in the SWIR) are negligible compared to the absorption terms. Then, only the direct transmission between the airborne and the TOA is considered. The algorithm is now applied to the TOA level radiance simulated from the airborne images and the results are shown in the figure 8 . Only few differences are visible between the concentration map of the plume with the data from satellite altitude (figure 8A) and with airborne data (figure 5B). This consistency is visible on the lineic masses shown in figure $8 \mathrm{~B}$ showing the mass per unit length for airborne initial data (blue curve) and for the data translated to the TOA (dashed red curve). These two curves are similar and the differences can be due to the detection step : the mask of present/absent plume pixel can generate false alarms in the edge of plume if the gas occupies a small part of the pixel.

\subsection{Spatial convolution}

The spatial resolution of new satellite hyperspectral imager as PRISMA (Labate et al., 2009) or EnMap (Guanter et al., 2015) is of $30 \mathrm{~m}$. As a reminder, the spatial resolution of AVIRIS image is of $6.8 \mathrm{~m}$. A first order reduction of the spatial resolution of images can be done by averaging a pixels square of the initial matrix. This convolution does not take into consideration the noise introduced by the averaging process or other perturbations which can be present in future satellite data.

We applied this convolution on the initial (airborne) images and the algorithm is then run. The figure 9A presents the concentration map of the plume for a spatial resolution up to $27.2 \mathrm{~m}$. The global shape of the plume is identifiable and stays similar

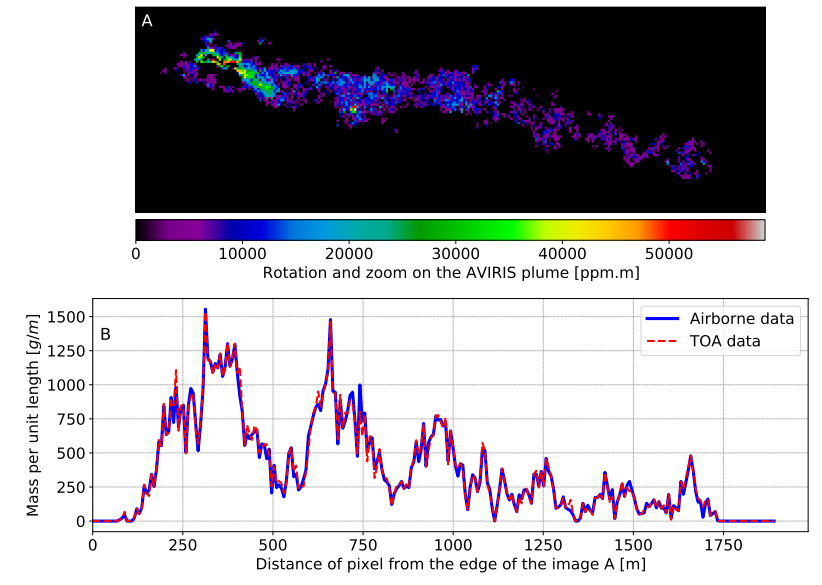

Figure 8. A : Concentration map zoom on the plume (in ppm.m) for TOA image. B : Mass per unit length (in $\mathrm{g} / \mathrm{m}$ ) along the plume (in $\mathrm{m}$ ) for airborne data, in blue, and for translation to TOA data, in red.

to the $6.8 \mathrm{~m}$ spatial resolution image (figure $8 \mathrm{~A}$ ). However, the mean mass per unit length presents more differences than the previous case. An important point is that the global shape of the curve at $27.2 \mathrm{~m}$ of spatial resolution is similar to the finer spatial resolution. As such, the plume detection and the estimation of its concentration seems still possible with satellite data. But, we can note that between 1000 and $1500 \mathrm{~m}$, an overestimation of the concentration occurs where the plume has a larger width than the other part (the tail plume). This may be due to averaging of pixels square at the initial step that emphasizes the spread of the plume. This will be investigated in the future.

The satellite data allow to detect and to quantify the plume in the case of the AVIRIS campaign plume with kilometric extension. The uncertainties of (simulated) satellite results are larger as shown by the figure $8 \mathrm{~B}$. The present work has to be continued to study the limits of the algorithm to detect and to quantify small plume and low intensity plumes from satellite data.
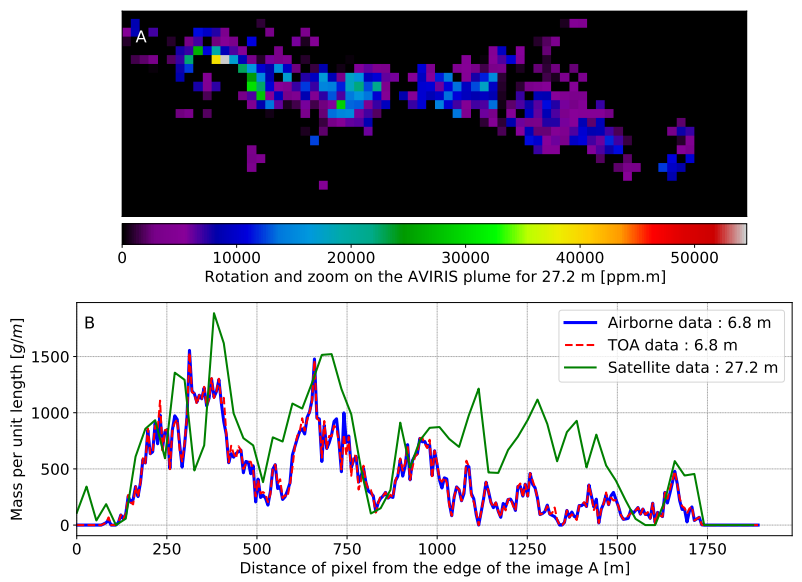

Figure 9. A : Concentration map zoom on the plume (in ppm.m) for TOA AVIRIS image with a spatial resolution of $27.2 \mathrm{~m}$. B : Mass per unit length (in $\mathrm{g} / \mathrm{m}$ ) along the plume (in $\mathrm{m}$ ) for different initial images. 


\section{CONCLUSION}

In this paper, we demonstrate the ability of our algorithm to detect $\mathrm{CH}_{4}$ plume and to quantify the flow rate of the source, with an uncertainty mainly due to the wind information. This characterization is carried out from the commercial HySpex camera using CTMF method in the detection step and using the plume transmission computation and LUT comparison to quantify the source. The algorithm detects a $60 \mathrm{~m}$ wide plume and a flow rate between 50 and $200 \mathrm{~g} / \mathrm{s}$ while the in situ measurement gives $75 \mathrm{~g} / \mathrm{s}$. The second part of this paper is dedicated to the algorithm results for simulated satellite images. For the both HySpex and AVIRIS, the translation to the TOA level has few impacts on the quantification of the plume. The study focuses on the absorption bands around $2.3 \mu \mathrm{m}$ that leads to some advantage since scattering effects can be neglected. As the HySpex plume is $60 \mathrm{~m}$ wide, we focus to the AVIRIS plume for the degradation of the spatial resolution. From $6.8 \mathrm{~m}$ (airborne resolution) to $27.2 \mathrm{~m}$ (near PRISMA or EnMap resolution), the algorithm is able to detect the plume and to estimate its concentration but a $27.2 \mathrm{~m}$ spatial resolution leads to a overestimation of the plume mean mass per unit length in the tail part. In the future, several points have to be investigated. The algorithm can be upgraded by reducing false alarms. The detection and quantification sensitivities of the algorithm should be investigated. Of course they will depend on the spatial and spectral resolution. This study can be conducted using synthetic data. Testing and validating this algorithm with true satellite data will be our final goal.

\section{ACKNOWLEDGEMENTS}

This research work has been performed within the framework of a CIFRE grant (ANRT) for the doctoral work of Nicolas Nesme.

\section{REFERENCES}

Bousquet, P., Ciais, P., Miller, J., Dlugokencky, E. J., Hauglustaine, D., Prigent, C., Van der Werf, G., Peylin, P., Brunke, E.-G., Carouge, C. et al., 2006. Contribution of anthropogenic and natural sources to atmospheric methane variability. Nature, 443(7110), 439-443.

Bradley, E. S., Leifer, I., Roberts, D. A., Dennison, P. E., Washburn, L., 2011. Detection of marine methane emissions with AVIRIS band ratios. Geophysical Research Letters, 38(10).

Crevoisier, C., Clerbaux, C., Guidard, V., Phulpin, T., Armante, R., Barret, B., Camy-Peyret, C., Chaboureau, J.-P., Coheur, P.-F., Crépeau, L. et al., 2014. Towards IASI-New Generation (IASI-NG): impact of improved spectral resolution and radiometric noise on the retrieval of thermodynamic, chemistry and climate variables.

Dlugokencky, E. J., Bruhwiler, L., White, J., Emmons, L., Novelli, P. C., Montzka, S. A., Masarie, K. A., Lang, P. M., Crotwell, A., Miller, J. B. et al., 2009. Observational constraints on recent increases in the atmospheric $\mathrm{CH} 4$ burden. Geophysical Research Letters, 36(18).

Etheridge, D. M., Steele, L., Francey, R., Langenfelds, R., 1998. Atmospheric methane between $1000 \mathrm{AD}$ and present: Evidence of anthropogenic emissions and climatic variability. Journal of Geophysical Research: Atmospheres, 103(D13), 15979-15993.
Forster, P., Ramaswamy, V., Artaxo, P., Berntsen, T., Betts, R., Fahey, D. W., Haywood, J., Lean, J., Lowe, D. C., Myhre, G. et al., 2007. Changes in atmospheric constituents and in radiative forcing. chapter 2. Climate Change 2007. The Physical Science Basis.

Funk, C. C., Theiler, J., Roberts, D. A., Borel, C. C., 2001. Clustering to improve matched filter detection of weak gas plumes in hyperspectral thermal imagery. IEEE transactions on geoscience and remote sensing, 39(7), 1410-1420.

Griggs, D. J., Noguer, M., 2002. Climate change 2001: the scientific basis. Contribution of working group I to the third assessment report of the intergovernmental panel on climate change. Weather, 57(8), 267-269.

Guanter, L., Kaufmann, H., Segl, K., Foerster, S., Rogass, C., Chabrillat, S., Kuester, T., Hollstein, A., Rossner, G., Chlebek, C. et al., 2015. The EnMAP spaceborne imaging spectroscopy mission for earth observation. Remote Sensing, 7(7), 8830-8857.

Houweling, S., Dentener, F., Lelieveld, J., 2000. Simulation of preindustrial atmospheric methane to constrain the global source strength of natural wetlands. Journal of Geophysical Research: Atmospheres, 105(D13), 17243-17255.

Hulley, G. C., Duren, R. M., Hopkins, F. M., Hook, S. J., Vance, N., Guillevic, P., Johnson, W. R., Eng, B. T., Mihaly, J. M., Jovanovic, V. M. et al., 2016. High spatial resolution imaging of methane and other trace gases with the airborne Hyperspectral Thermal Emission Spectrometer (HyTES). Atmospheric Measurement Techniques, 9(5), 2393-2408.

IPCC, C. C. et al., 2007. The physical science basis. Contribution of working group I to the fourth assessment report of the Intergovernmental Panel on Climate Change. Cambridge University Press, Cambridge, United Kingdom and New York, NY, USA, 996, 2007.

Kirschke, S., Bousquet, P., Ciais, P., Saunois, M., Canadell, J. G., Dlugokencky, E. J., Bergamaschi, P., Bergmann, D., Blake, D. R., Bruhwiler, L. et al., 2013. Three decades of global methane sources and sinks. Nature geoscience, 6(10), 813-823.

Labate, D., Ceccherini, M., Cisbani, A., De Cosmo, V., Galeazzi, C., Giunti, L., Melozzi, M., Pieraccini, S., Stagi, M., 2009. The PRISMA payload optomechanical design, a high performance instrument for a new hyperspectral mission. Acta Astronautica, 65(9-10), 1429-1436.

Lelieveld, J., Crutzen, P. J., Dentener, F. J., 1998. Changing concentration, lifetime and climate forcing of atmospheric methane. Tellus B, 50(2), 128-150.

Poutier, L., Miesch, C., Lenot, X., Achard, V., Boucher, Y., 2002. Comanche and cochise: two reciprocal atmospheric codes for hyperspectral remote sensing. 2002 AVIRIS Earth Science and Applications Workshop Proceedings, 1059-0889.

Sharpe, S. W., Johnson, T. J., Sams, R. L., Chu, P. M., Rhoderick, G. C., Johnson, P. A., 2004. Gas-phase databases for quantitative infrared spectroscopy. Applied spectroscopy, 58(12), $1452-1461$

Thompson, D., Leifer, I., Bovensmann, H., Eastwood, M., Fladeland, M., Frankenberg, C., Gerilowski, K., Green, R., Kratwurst, S., Krings, T. et al., 2015. Real-time remote detection and measurement for airborne imaging spectroscopy: a case study with methane. Atmos Meas Tech, 8(10), 4383-4397. 
Thompson, D., Thorpe, A., Frankenberg, C., Green, R., Duren, R., Guanter, L., Hollstein, A., Middleton, E., Ong, L., Ungar, S., 2016. Space-based remote imaging spectroscopy of the Aliso Canyon CH4 superemitter. Geophysical Research Letters, 43(12), 6571-6578.

Thorpe, A., Frankenberg, C., Roberts, D., 2014. Retrieval techniques for airborne imaging of methane concentrations using high spatial and moderate spectral resolution: Application to AVIRIS. Atmospheric Measurement Techniques, 7(2), 491506.

Thorpe, A. K., Frankenberg, C., Aubrey, A., Roberts, D., Nottrott, A., Rahn, T., Sauer, J., Dubey, M., Costigan, K., Arata, C. et al., 2016. Mapping methane concentrations from a controlled release experiment using the next generation airborne visible/infrared imaging spectrometer (AVIRIS-NG). Remote Sensing of Environment, 179, 104-115.

Veefkind, J., Aben, I., McMullan, K., Förster, H., De Vries, J., Otter, G., Claas, J., Eskes, H., De Haan, J., Kleipool, Q. et al., 2012. TROPOMI on the ESA Sentinel-5 Precursor: A GMES mission for global observations of the atmospheric composition for climate, air quality and ozone layer applications. Remote Sensing of Environment, 120, 70-83. 